\title{
UPLC Method for Simultaneous Separation and Estimation of Secnidazole, Fluconazole and Azithromycin in Pharmaceutical Dosage Forms
}

\author{
RAMESH YANAMANDRA $^{\S *}$, AVINASH CHAUDHARY ${ }^{\S}$, \\ SRINIVASA RAO BANDARU ${ }^{\S}$, BALARAM PATRO ${ }^{\S}$, Y.L.N. MURTHY\#, \\ PARIMI ATCHUTA RAMAIAH ${ }^{\#}$ and C. S. P. SASTRY \\ ${ }^{\S}$ Analytical Development Laboratory \\ GVK Biosciences Private Limited No.28A, Street No.15 \\ IDA, Nacharam, Hyderabad-500 076, India \\ "Department of Organic Chemistry \\ Food, Drugs and Water, A.U College of Science and Technology \\ Andhra University, Visakhapatnam-530 003, India \\ Prof (Retd.), Department of Organic Chemistry \\ Food, Drugs and Water, A.U College of Science and Technology \\ Andhra University, Visakhapatnam-530 003, India \\ ramesh.yanamandra@gvkbio.com
}

Received 18 April 2010; Accepted 10 June 2010

\begin{abstract}
A novel approach was carried out to develop and validate a rapid, specific, accurate and precise reverse phase ultra performance liquid chromatographic (UPLC) method for the simultaneous separation and quantification of secnidazole, fluconazole and azithromycin in pharmaceutical dosage forms. The developed analytical method is superior in technology to conventional HPLC with respect to time, resolution, solvent consumption and cost of analysis. Elution time for the separation was $10 \mathrm{~min}$ and ultra violet detection was carried out at $210 \mathrm{~nm}$. Efficient separation was achieved on BEH C18 sub-2$\mu \mathrm{m}$ UPLC column using $0.002 \mathrm{M} \mathrm{Na}_{2} \mathrm{HPO}_{4}$ and acetonitrile as organic solvent in a gradient program. Benzophenone was used as internal standard. Resolutions between secnidazole, fluconazole and azithromycin were found to be more than 4.8. The calibration graphs were linear for secnidazole, fluconazole, benzophenone and azithromycin. The method showed excellent recoveries for all dosage forms. The test solution was found to be stable in diluent for $72 \mathrm{~h}$ when stored in the refrigerator between 2 to $8{ }^{\circ} \mathrm{C}$. The proposed UPLC method was validated with respect to linearity, accuracy, precision, specificity and robustness and can be used for the simultaneous estimation of secnidazole, fluconazole and azithromycin in tablet dosage forms available as a combi kit.
\end{abstract}

Keywords: UPLC, Secnidazole, Fluconazole, Azithromycin, Validation, Simultaneous estimation. 


\section{Introduction}

Ultra performance liquid chromatography (UPLC) is an innovative product that brought revolution in high performance liquid chromatography by outperforming conventional HPLC. UPLC decreases sample run times up to a factor of 10 , uses up to 95 percent less solvent and significantly improves productivity in the lab. The sub-2- $\mu \mathrm{m}$ hybrid particle chemistry, which offers significant benefits over today's HPLC systems equipped with standard 5- $\mu \mathrm{m}$ particle chemistries. UPLC achieves the speed by using novel sub twomicron particles that decreases chromatographic run times and also double peak capacity or resolution. UPLC was designed as a total system to leverage both ultra-high pressure and small particle separation attributes that result in uniquely superior performance. With significant improvements in resolution, sensitivity and speed that can be achieved for chromatographic separations by minimizing the band spreading contributions of both the instrument and the column.

UPLC system will eliminate significant time and cost per sample from analytical process while improving the quality of results, the system allows chromatographers to work at higher efficiencies with a much wider range of linear velocities, flow rates and backpressures. UPLC photodiode array (PDA) detector detects and quantifies lower concentrations of sample analyte, trace impurities at levels to $0.004 \%$ with maximum sensitivity and compares spectra across wavelengths and broad concentration ranges. It is easy to identify components that are difficult to detect by conventional HPLC-based methods. To the best of our knowledge, a validated reverse phase UPLC method for the simultaneous separation and estimation of secnidazole, fluconazole and azithromycin disclosed in this investigation was not published elsewhere which is described in this investigation.

Secnidazole (SNZ; CAS 3366-95-8) is a nitroimidazole drug $^{1}$, an orally active antiamoebic, antiprotozoal drug used for the treatment of infection ${ }^{2}$. In an infection, the infecting organism seeks to utilize the host's resources to multiply. The injecting organism, or pathogen, interferes with the normal functioning of the host and can lead to chronic wounds, gangrene, loss of an infected limb and even death. SNZ has the chemical name (1-(2-methyl-5-nitro-1H-imidazol-1-yl) propan-2-ol). SNZ molecular formula is $\mathrm{C}_{7} \mathrm{H}_{11} \mathrm{~N}_{3} \mathrm{O}_{3}$, and a molecular weight of 185.18. It is available as a tablet and usually 2 grams single dosed with food. Fluconazole (FCZ; CAS 86386-73-4) is a triazole group drug ${ }^{3}$, an orally active used in the treatment and precention of superficial and systemic fungal infections. Like other imidazole and triazole class antifungals, fluconazole inhibits the fungal cytochrome P450 enzyme $14 \alpha$-demethylase. This inhibition prevents the conversion of lanosterol to ergosterol, an essential component of the fungal cytoplasmic membrane and subsequent accumulation of $14 \alpha$-methyl sterols. Fluconazole is primarily fungi static. FCZ has the chemical name (2-(2,4-difluorophenyl)-1,3-bis(1H-1,2,4-triazol-1-yl)propan-2-ol). FCZ molecular formula is $\mathrm{C}_{13} \mathrm{H}_{12} \mathrm{~F}_{2} \mathrm{~N}_{6} \mathrm{O}$ and a molecular weight of 306.27 . It is available as a tablet and usually dosed once daily after breakfast. Azithromycin (AZTM; CAS 83905-01-5) is the first clinically developed antibiotic in a new subclass of the macrolides, is one of the world's best-selling antibiotics and is derived from erythromycin. The azalides, characterized by the expansion of the 14-membered aglycone ring of erythromycin with endocyclic ionizable nitrogen $^{4,5}$. AZTM has the chemical name $(2 R, 3 S, 4 R, 5 R, 8 R, 10 R, 11 R, 12 S, 13 S, 14 R)$-2-ethyl3,4,10-trihydroxy-3,5,6,8,10,12,14-heptamethyl-15-oxo-11-\{[3,4,6-trideoxy-3-(dimethylamino)$\beta$-D-xylo-hexopyranosyl]oxy\}-1-oxa-6-azacyclopentadec-13-yl 2,6-dideoxy-3- $C$-methyl-3- $O$ methyl- $\alpha$ - $L$-ribo-hexopyranoside). A methyl-substituted nitrogen atom is incorporated into the lactone ring, thus making the lactone ring 15-membered onto which two 
sugar moieties are linked. The insertion of methyl-substituted nitrogen on the lactone ring at position 9a of the large macrolactone ring produces an enhanced spectrum and potency against bacteria compared with other macrolides and erythromycin ${ }^{6,7}$ and superior stability in acidic environment ${ }^{8}$. AZTM molecular formula is $\mathrm{C}_{38} \mathrm{H}_{72} \mathrm{~N}_{2} \mathrm{O}_{12}$ and a molecular weight of 748.98. It is reported to exist extensively as dihydrate ${ }^{9}$, with a molecular formula of $\mathrm{C}_{38} \mathrm{H}_{72} \mathrm{~N}_{2} \mathrm{O}_{12} 2 \mathrm{H}_{2} \mathrm{O}$ and a molecular weight of $785.0^{10}$. AZTM does not interact with the hepatic cytochrome P450 system and is not associated with the pharmacokinetic drug interactions seen with erythromycin and other macrolides ${ }^{11}$. It is available as a tablet and usually dosed $1 \mathrm{~h}$ before or $2 \mathrm{~h}$ after meal. The combination kit with azithromycin, secnidazole and fluconazole was more effective with better symptomatic relief and less recurrence rate and may be routinely recommended in all cases of lower genital infection and syndromic management of pelvic inflammatory disease in a cost effective, safe and effective strategy ${ }^{12,13}$.

A few analytical methods have been reported for the individual estimation of secnidazole ${ }^{14,15}$, fluconazole ${ }^{16}$ and azithromycin ${ }^{17,18}$. A review of the literature did not reveal the presence of simultaneous method applied to the separation and estimation of above three drugs by UPLC technique. The aim of this work was to develop sensitive, accurate, precise, rapid and validated UPLC method for the separation and estimation of three drugs by a single method. The proposed reverse phase UPLC method has the advantage of simultaneous estimation of these three drugs in a short span of $10 \mathrm{~min}$ run time and the method was applied to dosage forms successfully. The proposed analytical method was validated according to ICH guidelines with respect to precision, linearity, accuracy, specificity and robustness ${ }^{19}$.

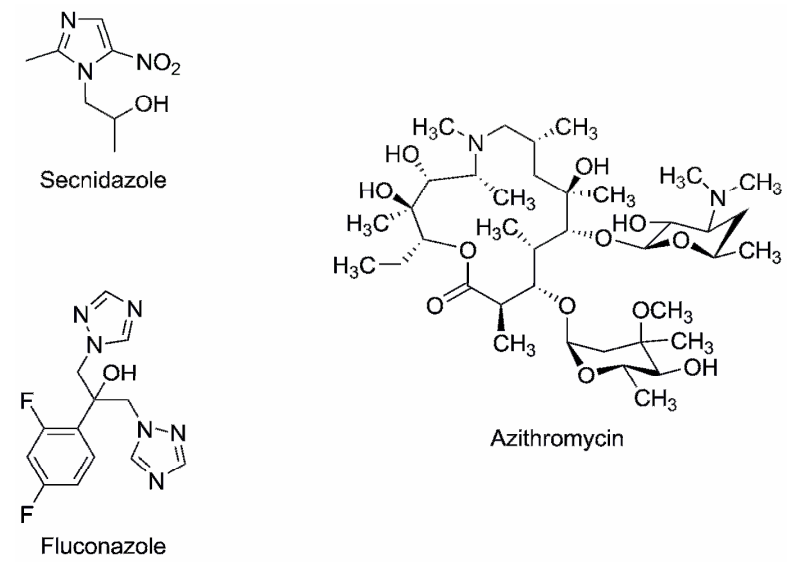

Figure 1. Chemical structure of secnidazole, fluconazole and azithromycin

\section{Experimental}

Bulk sample of fluconazole was obtained from Auctus Pharma (Hyderabad, India). secnidazole and azithromycin were obtained from Alchem Laboratories Ltd. (Mumbai, India). Commercially available FAS-3 combikit manufacture by Hetero Healthcare Ltd and ZOCON-AS combikit manufacture by FDC Limited was purchased from local pharmacy each containing one tablet of fluconazole $(150 \mathrm{mg})$, two tablets of secnidazole $(1 \mathrm{~g} \mathrm{each})$, and one tablet of azithromycin $(1 \mathrm{~g})$ as individual dosage forms in a blister pack. HPLC grade acetonitrile, methanol were obtained from Apchem, Ashonuj Chem Pvt. Ltd (Navi Mumbai, India). $\mathrm{Na}_{2} \mathrm{HPO}_{4}$ and $\mathrm{NaOH}$ were obtained from Merck (Darmstadt, Germany), Benzophenone was obtained from Alfa Aesar, Lancaster. High purity water was obtained 
from Millipore Milli-Q Plus water purification system. The chromatographic separation and quantification was carried out on a Waters Acquity UPLC with PDA Detector with a separation module. Empower software (Waters) was used for data handling installed on a Pentium computer (Lenovo). Acquity BEH-Shield RP18 and BEH-C18 columns were purchased from Waters.

\section{Chromatographic conditions}

The analysis was carried out on Acquity BEH-Shield RP18 column $(100 \times 2.1 \mathrm{~mm}, 1.7 \mu)$. The mobile phase composition was the buffer $0.002 \mathrm{M} \mathrm{Na}_{2} \mathrm{HPO}_{4}$ (pH adjusted to 10.0 with $3 \%$ aq. $\mathrm{NaOH}$ solution) and acetonitrile filtered by using $0.45 \mu \mathrm{m}$ filter and degassed prior to use with a linear time gradient program (Time $(\mathrm{min}) / \%$ acetonitrile: 0/5, 1.5/5, 3/30, 5/90, $8 / 90,9 / 5,10 / 5)$. The column temperature was $40{ }^{\circ} \mathrm{C}$ and detection was monitored at $210 \mathrm{~nm}$. The injection volume was $0.5 \mu \mathrm{L}$ and acetonitrile and methanol $(50: 50, v / v)$ was used as sample diluent. The flow rate of the mobile phase was maintained at $0.3 \mathrm{~mL} / \mathrm{min}$ and the total analysis run time was $10 \mathrm{~min}$.

\section{RP-UPLC assay procedure}

Twenty tablets each containing $150 \mathrm{mg}$ of fluconazole (FCZ), $1000 \mathrm{mg}$ of secnidazole (SNZ) and $1000 \mathrm{mg}$ of azithromycin (AZTM) were weighed individually to determine the average tablet weight and powdered in a mortar. A quantity of powder equivalent to $40.0 \mathrm{mg}$ of FCZ, $80.0 \mathrm{mg}$ of SNZ, $1000.0 \mathrm{mg}$ of AZTM and $20.0 \mathrm{mg}$ of benzophenone (BNPN) were weighed and transferred to $100 \mathrm{~mL}$ volumetric flask. About $50 \mathrm{~mL}$ diluent was added and kept on a rotary shaker for $20 \mathrm{~min}$ to disperse the material completely followed by sonication for $10 \mathrm{~min}$, cooled to room temperature, made up to mark with diluent and mixed well. About $10 \mathrm{~mL}$ of sample solution was centrifuged for $15 \mathrm{~min}$ at 2,500 rpm. The supernatant was collected and filtered through a $0.45 \mu \mathrm{m}$ Nylon-66 membrane filter. The tablets sample solution was injected and the chromatogram was obtained. The peak area of the fluconazole, secnidazole, azithromycin and benzophenone was calculated. Using the regression equations and the peak area of the samples the amount of the drug present in the sample was calculated. The amount of fluconazole, secnidazole and azithromycin per tablet was thus found.

\section{Method validation}

Stock solutions of secnidazole, fluconazole, azithromycin and benzophenone $1600 \mu \mathrm{g} / \mathrm{mL}$, $800 \mu \mathrm{g} / \mathrm{mL}, 20,000 \mu \mathrm{g} / \mathrm{mL}$ and $400 \mu \mathrm{g} / \mathrm{mL}$ were prepared respectively by dissolving the appropriate amount in acetonitrile and methanol $(50: 50 \mathrm{v} / \mathrm{v})$ and diluted to the required concentrations. Linearity of the method was studied by injecting five concentrations of the drug each three replicate injections prepared in the diluent in the range of $25 \%$ to $120 \%$ of the target concentration of SNZ (200-960 $\mu \mathrm{g} / \mathrm{mL})$, FCZ $(100-480 \mu \mathrm{g} / \mathrm{mL})$, AZTM $(2500$ $12,000 \mu \mathrm{g} / \mathrm{mL})$ and BNPN $(50-240 \mu \mathrm{g} / \mathrm{mL})$ into the UPLC system and noting the peak areas. A linear graph was plotted by using the peak areas against concentration in $\mu \mathrm{g} / \mathrm{mL}$. The correlation coefficients, slopes and $Y$-intercepts of the calibration curve were determined.

The precision of the proposed method was evaluated by the study of the repeatability (system precision), reproducibility (method precision) and intermediate precision. The repeatability was checked by making six replicate injections of the target concentration and $\%$ RSD of three drugs and BNPN was calculated for peak areas, USP tailing factor and plate count. For reproducibility six different preparations of mixture of three drugs and BNPN were analyzed. The intermediate precision was performed by a second analyst on a different day using a different instrument. 


\section{Accuracy}

The accuracy of the method was determined by calculating recoveries of SNZ, FCZ, AZTM, and BNPN by placebo spiked method. The recovery studies were carried out at 80, 100 and $120 \%$ for three replicate injections of each concentration of the analyte followed by calculation percentage recovery. Known amounts of SNZ (640, 800 and $960 \mu \mathrm{g} / \mathrm{mL}), \mathrm{FCZ}$ (320, 400 and $480 \mu \mathrm{g} / \mathrm{mL}), \operatorname{AZTM}(8,000,10,000$ and 12,000 $\mu \mathrm{g} / \mathrm{mL})$ and BNPN $(160,200$ and $240 \mu \mathrm{g} / \mathrm{mL}$ ) were added to placebo preparation and the amount of SNZ, FCZ, AZTM, and BNPN were estimated by measuring the peak areas.

\section{Solution stability and mobile phase stability}

Solution stability of three drugs solution along with benzophenone in a tightly capped volumetric flask for $72 \mathrm{~h}$ when stored in a refrigerator between 2 to $8{ }^{\circ} \mathrm{C}$ temperatures was studied. The contents of three drugs were determined in $8 \mathrm{~h}$ intervals. Mobile phase stability was assessed over a period of $72 \mathrm{~h}$ by injecting the freshly prepared sample solutions in $8 \mathrm{~h}$ interval as well. The contents of three drugs were determined in the test solutions.

\section{Specificity}

The specificity of the analytical method was checked in different conditions of acid hydrolysis $(0.1 \mathrm{~N} \mathrm{HCl})$, base hydrolysis $(0.1 \mathrm{~N} \mathrm{NaOH})$ and peroxide treatment $\left(0.3 \% \mathrm{H}_{2} \mathrm{O}_{2}\right)$. Aliquot quantities of mixture of three drugs were weighed in different volumetric flasks and added $3.0 \mathrm{~mL}$ of $0.1 \mathrm{~N} \mathrm{HCl}, 3.0 \mathrm{~mL}$ of $0.1 \mathrm{~N} \mathrm{NaOH}$ and $1.0 \mathrm{~mL}$ of $0.3 \% \mathrm{H}_{2} \mathrm{O}_{2}$ respectively and diluted to $75 \mathrm{~mL}$ with diluent. These solutions were refluxed at $80^{\circ} \mathrm{C}$ for $8 \mathrm{~h}$, cooled to room temperature, made up to $100 \mathrm{~mL}$ with diluent and analyzed by UPLC.

\section{Robustness}

The experimental conditions were deliberately altered and resolution between SNZ, FCZ, BNPN and AZTM was evaluated to check the robustness of the method. The impact of flow rate and temperature changes on resolution, tailing factor and plate count was studied by flow rate alteration $\pm 0.05 \mathrm{~mL} / \mathrm{min}$ and column temperature $\pm 5^{\circ} \mathrm{C}$. The mobile phase composition and injection volume was kept constant. The effect of different column dimension was also studied.

\section{Results and Discussion}

The aim of this work was to develop a fast, sensitive, precise and accurate reverse phase UPLC method for the simultaneous separation and estimation of SNZ, FCZ and AZTM. To optimize the proposed RP-UPLC method all of the experimental conditions were investigated. As part of the preliminary work, separation was attempted using BEH C18 $(100 \times 2.1 \mathrm{~mm}, 1.7 \mu)$ column with $0.002 \mathrm{M}$ ammonium acetate buffer and acetonitrile in different gradient programs at a flow rate of $0.3 \mathrm{~mL} / \mathrm{min}$. The sensitivity of SNZ and FCZ was poor with unsymmetrical peak shapes and AZTM was not even detected at common UV maxima of $210 \mathrm{~nm}$. Separation between SNZ and FCZ was only $0.2 \mathrm{~min}$ in a total run time of $10 \mathrm{~min}$. Trials were also done at acidic $\mathrm{pH}$ as there was no improvement in sensitivity of AZTM but there was considerable improvement for SNZ and FCZ. BNPN peak shape and sensitivity was good in all above trials. It was found in the literature that AZTM has two $\mathrm{pKa}$ values at 8.1 and 8.9. Attempts were made with different basic $\mathrm{pH}$ in a range of \pm 2.0 $\mathrm{pKa}$. Triethylamine (TEA) was used to adjust the buffer $\mathrm{pH}$ to 10.0 which has shown dramatic improvement in sensitivity of AZTM, but found noise in chromatography. To optimize the mobile phase, different systems were tried for chromatographic separation of 
the three components by combining homogeneous design and solvent polarity optimization. The best resolution was achieved using a mobile phase consisting of $0.002 \mathrm{M} \mathrm{Na}_{2} \mathrm{HPO}_{4}$ ' pH adjusted to 10.0 with $3 \%$ aq. $\mathrm{NaOH}$ and acetonitrile as organic phase which gave good resolution and sensitivity for all three drugs. Trials were also done at different flow rates and different temperatures to optimize the peak shape, sensitivity, tailing factor and resolution for all three drugs and BNPN. The choice of C18 columns in UPLC is limited to BEH-C18 and BEH-Shield RP18 in reverse phase conditions.
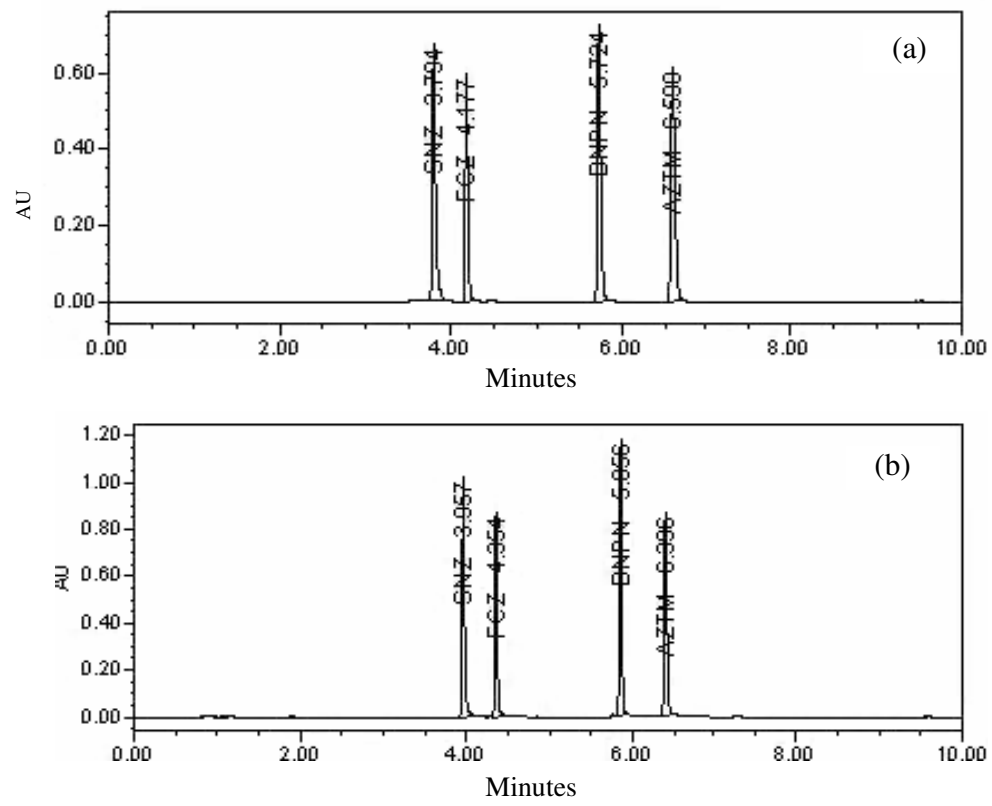

Figure 2. Representative chromatograms of secnidazole, fluconazole, benzophenone and azithromycin. (Flow rate : (a) $0.3 \mathrm{~mL} / \mathrm{min}$; (b) $0.25 \mathrm{~mL} / \mathrm{min}$ )

\section{Precision}

System suitability testing of the RP-UPLC method gave good retention time of 3.7, 4.1, 5.6, and 6.2 min for SNZ, FCZ, BNPN and AZTM respectively. The resolution between secnidazole and fluconazole was 4.8, fluconazole and benzophenone was 19.0 and benzophenone and azithromycin was 5.7. The number of theoretical plates, USP tailing factor, capacity factor, $\%$ RSD $(n=6)$ for SNZ, FCZ, BNPN and AZTM are summarized in Table 1. The area \%RSD values for SNZ, FCZ, BNPN and AZTM were found to be within $2.0 \%$ confirming a suitable precision of the method.

\section{Linearity}

The data obtained in the calibration experiments when subjected to linear regression analysis showed a linear relationship between peak areas and concentrations of the three drugs in the range of $200-960 \mu \mathrm{g} / \mathrm{mL}, 100-480 \mu \mathrm{g} / \mathrm{mL}, 2500-12,000 \mu \mathrm{g} / \mathrm{mL}$ and $50-240 \mu \mathrm{g} / \mathrm{mL}$ for SNZ, FCZ, AZTM and BNPN respectively. The correlation coefficient obtained was greater than 0.99 for all drugs. The linear regression equation, Slope and $Y$-Intercept values were computed, $\mathrm{Y}=14750 \mathrm{X}+65791, \mathrm{r}=0.995$ for secnidazole; $\mathrm{Y}=9631 \mathrm{X}+47218, \mathrm{r}=0.996$ for fluconazole; $Y=15676 x+75228, \quad r=0.995$ for benzophenone and $Y=15551 x+92418, \quad r=0.992$ for azithromycin respectively where $Y$ is the area under the peak, $X$ is the concentration in $\mu \mathrm{g} / \mathrm{mL}$ and ' $r$ ' is the correlation coefficient. The \%RSD values of the slope and $Y$-intercept values 
were 0.9 and $7.7 \%, 0.7$ and $5.3 \%, 0.7$ and $7.1 \%$ and 0.4 and $1.8 \%$ for SNZ, FCZ, BNPN and AZTM respectively which confirmed the linear relationship between peak areas and concentrations. The Linearity test results are summarized in Table 2.

Table 1. System suitability test parameters for SNZ, FCZ and AZTM for proposed method

\begin{tabular}{lccc}
\hline \multirow{2}{*}{ Parameters } & \multicolumn{3}{c}{ RP-UPLC method } \\
\cline { 2 - 4 } & SNZ $\pm \%$ RSD & FCZ $\pm \%$ RSD & AZTM $\pm \%$ RSD \\
\hline Retention time, min & $3.7 \pm 0.3$ & $4.1 \pm 0.1$ & $6.2 \pm 0.0$ \\
Resolution & - & 7.8 & 11.1 \\
Theoretical plates & $53669 \pm 1.16$ & $162676 \pm 1.02$ & $270009 \pm 1.21$ \\
USP Tailing & $1.8 \pm 0.8$ & $1.4 \pm 1.1$ & $1.4 \pm 0.62$ \\
$\begin{array}{l}\text { Capacity factor } \\
\text { Repeatability of measurement } \\
(\mathrm{n}=6)\end{array}$ & $2.7 \pm 0.63$ & $3.1 \pm 0.71$ & $5.2 \pm 0.28$ \\
\hline
\end{tabular}

$R S D$ is relative standard deviation, $n$ is number of determinations

Table 2. Results of regression analysis data for SNZ, FCZ and AZTM for proposed method

\begin{tabular}{llll}
\hline Linearity $(\mathrm{n}=6)$ & SNZ & FCZ & AZTM \\
Correlation coefficient $(\mathrm{r})$ & 0.995 & 0.996 & 0.992 \\
Slope & 14749.7 & 9631.3 & 15551.0 \\
Intercept & 65790.7 & 47218.0 & 92417.7 \\
\%RSD for Slope & 0.9 & 0.7 & 0.4 \\
\%RSD for Intercept & 7.7 & 5.3 & 1.8 \\
\hline
\end{tabular}

$n$ is number of determinations

\section{Accuracy}

The percentage recovery obtained for SNZ, FCZ and AZTM ranged from 95.0\% and 105.0\%. The Accuracy test results are summarized in Table 3.

Table 3. Results of recovery studies for snz, fcz and aztm for proposed method

\begin{tabular}{ccccccc}
\hline \multirow{2}{*}{$\begin{array}{c}\text { Level of } \\
\text { \% Recovery } \\
(\mathrm{n}=3)\end{array}$} & \multicolumn{3}{c}{$\begin{array}{c}\text { Amt. of Pure } \\
\text { Drug Added, mg }\end{array}$} & \multicolumn{3}{c}{$\%$ Recovery } \\
\cline { 2 - 7 } & SNZ & FCZ & AZTM & SNZ & FCZ & AZTM \\
\hline 80 & 64 & 32 & 800 & 99.58 & 100.80 & 98.81 \\
100 & 80 & 40 & 1000 & 100.41 & 100.25 & 100.62 \\
120 & 96 & 48 & 1200 & 100.60 & 99.62 & 100.25 \\
& Mean \% Recovery & & 100.20 & 100.22 & 99.89 \\
& SD & & 0.5424 & 0.5905 & 0.9563 \\
& CV & & 0.0054 & 0.0059 & 0.0096 \\
\hline
\end{tabular}

\section{Solution stability and mobile phase stability}

No significant changes were observed in the content of SNZ, FCZ, BNPN and AZTM during solution and mobile phase stability experiments. The stability data confirmed that sample solutions were stable up to $72 \mathrm{~h}$ when stored in a refrigerator between 2 to $8{ }^{\circ} \mathrm{C}$ temperature.

\section{Specificity}

Degradation was not found in acid hydrolysis and peroxide treatment samples, but found $31 \%$ and $25 \%$ of degradation in base hydrolysis for both bulk drugs and dosage forms. Degradants that are formed have base line chromatographic resolution with main components. Specificity was also confirmed by peak purity values given by PDA detector and the purity flags pass for SNZ, FCZ and AZTM indicates non-interference by matrix components. Hence the method is specific. 


\section{Robustness}

Potential interferences from excipients (dibasic calcium phosphate anhydrous, pregelatinized starch, croscarmellose sodium, lactose, magnesium stearate, microcrystalline cellulose, povidone, hypromellose, titanium dioxide, sodium lauryl sulfate, triacetin and ponceau 4R) were also investigated. The commonly used tablet excipients were subjected to chromatographic analysis and were observed for any of the interfering peaks at the retention time of SNZ, FCZ, AZTM and BNPN and the effect on the area of peak of interest and retention time was noted and found no interferences from excipients were observed with resolution values greater than 5.0 between SNZ, FCZ, BNPN and AZTM illustrating a good robustness of the method. The Robustness test results are summarized in Table 4.

Table 4. Robustness results

\begin{tabular}{cccc}
\hline Robustness & $\begin{array}{c}\mathrm{SNZ} \\
\left(\mathrm{R}_{\mathrm{t}}\right)\end{array}$ & $\begin{array}{c}\mathrm{FCZ} \\
\left(\mathrm{R}_{\mathrm{t},} \mathrm{R}_{\mathrm{S}}\right)\end{array}$ & $\begin{array}{c}\text { AZTM } \\
\left(\mathrm{R}_{\mathrm{t},} \mathrm{R}_{\mathrm{S}}\right)\end{array}$ \\
\hline Different flow $0.25 \mathrm{~mL} / \mathrm{min}$ & 4.0 & $4.3,7.7$ & $6.4,9.2$ \\
$0.35 \mathrm{~mL} / \mathrm{min}$ & 3.3 & $3.8,10.8$ & $5.8,10.5$ \\
Different Temp. $35^{\circ} \mathrm{C}$ & 3.7 & $4.1,9.3$ & $6.0,8.3$ \\
$45^{\circ} \mathrm{C}$ & 3.6 & $4.0,9.9$ & $6.0,9.0$ \\
Different Column: Acquity & & & \\
BEH-C18 (50 x $2.1 \mathrm{~mm}, 1.7 \mu)$ & & & \\
Different flow $0.25 \mathrm{~mL} / \mathrm{min}$ & 3.3 & $3.7,5.3$ & $5.9,6.9$ \\
$0.35 \mathrm{~mL} / \mathrm{min}$ & 2.9 & $3.4,9.4$ & $5.6,13.0$ \\
Different Temp. $35^{\circ} \mathrm{C}$ & 3.0 & $3.5,9.3$ & $5.7,10.6$ \\
$45^{\circ} \mathrm{C}$ & 2.9 & $3.5,7.5$ & $5.6,9.1$ \\
Different pH 10.2 & 3.7 & $4.1,9.7$ & $6.2,7.4$ \\
$\mathrm{pH} 9.8$ & 3.5 & $3.9,8.7$ & $5.9,7.2$ \\
\hline
\end{tabular}

$\mathrm{R}_{\mathrm{t}}$ retention time in minutes, $\mathrm{R}_{\mathrm{s}:}$ USP resolution

Results obtained by applying the proposed RP-UPLC procedure showed that SNZ, FCZ and AZTM can be simultaneously analyzed in the prepared mixtures. The assay was calculated from the equation of regression line and the percentage of drug with mean recoveries found in the formulation was $100.20 \pm 0.54,100.22 \pm 0.58$, and $99.89 \pm 0.95 \%$ for SNZ, FCZ and AZTM respectively. The results of analysis show that the amount of drug was in good agreement with the label claim of the formulation. The proposed method has been applied successfully to assay SNZ, FCZ and AZTM in combikit product of Hetero Healthcare Ltd. and FDC Limited manufacturer each three batches $(n=3)$. In all batches the contents of SNZ, FCZ, and AZTM were well within the limits of $\geq 90.0 \%$ and $\leq 110.0 \%$ $(\mathrm{w} / \mathrm{w})$ and the results are summarized in Table 5.

Table 5. Assay results for tablets using proposed method

\begin{tabular}{|c|c|c|c|c|c|c|c|c|}
\hline \multirow[t]{2}{*}{ Formulation } & \multicolumn{2}{|c|}{$\begin{array}{l}\text { Amount of drug } \\
\text { taken, mg }\end{array}$} & \multicolumn{3}{|c|}{$\begin{array}{l}\text { Amount of drug } \\
\text { found, mg }\end{array}$} & \multicolumn{3}{|c|}{$\begin{array}{l}\% \text { Amount found } \\
(\mathrm{n}=3) \pm \mathrm{SD}\end{array}$} \\
\hline & SNZ FCZ & AZTM & SNZ & FCZ & AZTM & SNZ & $\mathrm{FCZ}$ & AZTM \\
\hline FAS-3 kit & 81.8748 .73 & 1032.9 & 82.00 & 48.79 & 1010.48 & $100.15 \pm 1.04$ & $100.12 \pm 0.68$ & $97.83 \pm 1.30$ \\
\hline $\begin{array}{l}\text { ZOCON- } \\
\text { AS kit }\end{array}$ & $79.94 \quad 40.32$ & 1000.07 & 78.15 & 39.46 & 981.7 & $97.77 \pm 0.32$ & $97.86 \pm 0.76$ & $98.17 \pm 1.18$ \\
\hline
\end{tabular}




\section{Conclusion}

An accurate and reliable reverse phase UPLC method was proposed for the separation and simultaneous estimation of SNZ, FCZ and AZTM. The buffer choice and $\mathrm{pH} 10.0$ with 3\% aq. $\mathrm{NaOH}$ solution were found to be crucial in the separation of these drugs. Based on the results obtained, it is found that the proposed method is accurate, precise, reproducible, rapid and economical and can be used in routine analysis of combination kit product containing secnidazole, fluconazole and azithromycin dosage forms.

\section{Acknowledgment}

The authors wish to thank the management, Dr. Sharfuddin Mohammed and other colleagues of GVK Bio Sciences Private Ltd. Hyderabad, India, for their support to carry out this investigation.

\section{References}

1. Jokipii L and Jokipii A M, Antimicrob Agents Chemother., 1985, 28(4), 561-564.

2. Gillis J C and Wiseman L R, Drugs, 1996, 51, 621-638.

3. Washton H, Diagn Microbiol Infect Dis., 1989, 12, 2295.

4. Bright G M, Nagel A A, Bordner J, Desai K A, Dibrino J N, Nowakowska J, Vincent L, Watrous R M and Sciavolino F C, J Antibiot., 1988, 41, 1029-1047.

5. Van Bambeke F, Montenez J P, Piret J, Tulkens P M, Courtoy P J and Mingeot-Leclercq M P, Eur J Pharmacol., 1996, 314(1-2), 203-214.

6. Shepard R M, Duthu G S, Ferraina R A and Mullins M A, J Chromatogr A.,1991, 565, 321-337.

7. $\quad$ Ripa S, Ferrante L and Prenna M, Chemotherapy, 1996, 42(6), 402-409.

8. Farghaly O A E-M and Mohamed N A L, Talanta, 2004, 62, 531.

9. Gandhi R, Pillai O, Thilagavathi R, Gopalakrishnan B, Kaul C L and Panchagnula R, Eur J Pharm Sci., 2002, 16, 175-184.

10. $\quad$ Miguel L and Barbas C, J Pharm Biomed Anal., 2003, 33, 211-217.

11. Dunn C J and Barradell L B, Drugs, 1996, 51(3), 483-505.

12. Sharma J B, Mittal S, Raina U and Chanana C, Archives of Gynecology and Obstetrics, 2006, 273, 232-235.

13. Malhotra M, Sharma J B, Batra S, Arora R and Sharma S, Indian J Med Sci 2003, 57, 549-555.

14. Walily A F M, Abdine H H, Razak O A and Zamel S, J Pharm Biomed Anal., 2000, 22(6), 887.

15. Moustafa A A and Bibawy L I, Spectrosc Lett., 1999, 32, 1073-1098.

16. Wallace J E, Harris S C, Gallegos J, Foulds G, Chen T J and Rinaldi M G, Antimicrob Agents Chemother., 1992, 36(3), 603-606.

17. Zubata P, Ceresole R, Rosasco M A and Pizzorno M T, J Pharm Biomed Anal., 2002, 27(5), 833-836.

18. Kovačić-Bošnjak N, Marincel J, Lopotar N and Kobrehel G, Chromatographia, 1988, 25(11), 999-1003.

19. International Conferences on Harmonization Q2(R1), Validation of analytical Procedures: Text and methodology, 2005. 


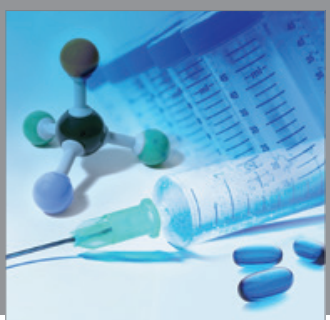

International Journal of

Medicinal Chemistry

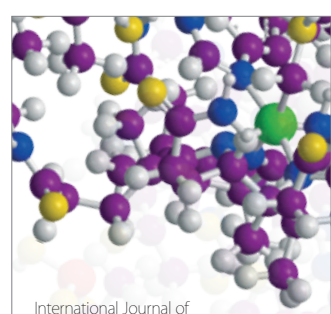

Carbohydrate Chemistry

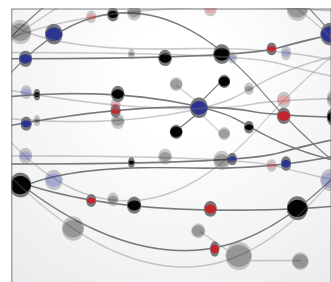

The Scientific World Journal
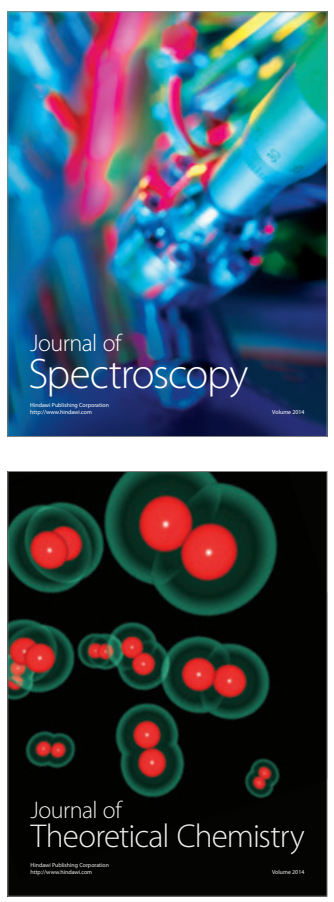
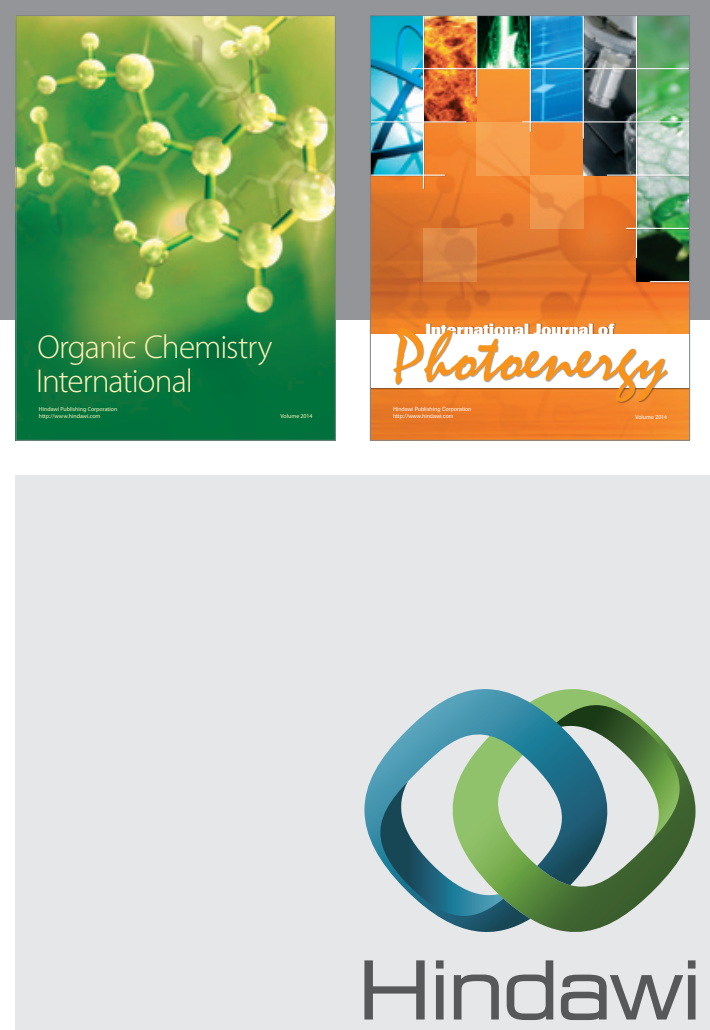

Submit your manuscripts at

http://www.hindawi.com
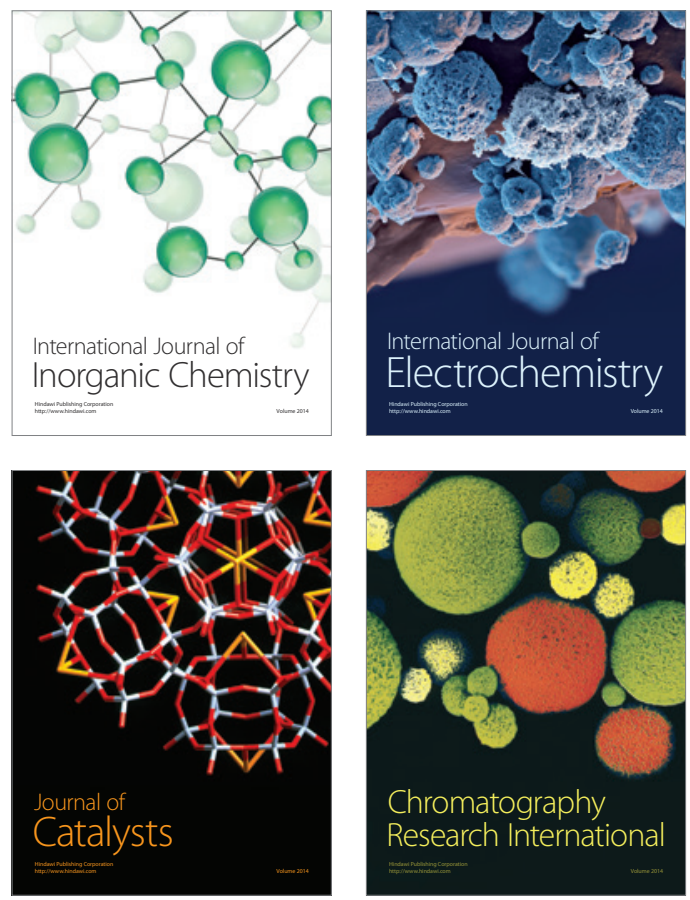
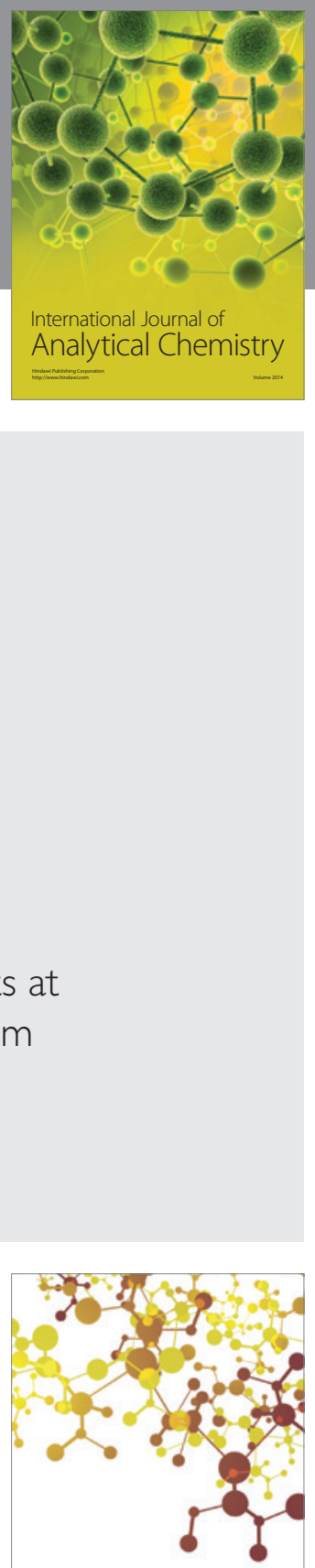

Journal of

Applied Chemistry
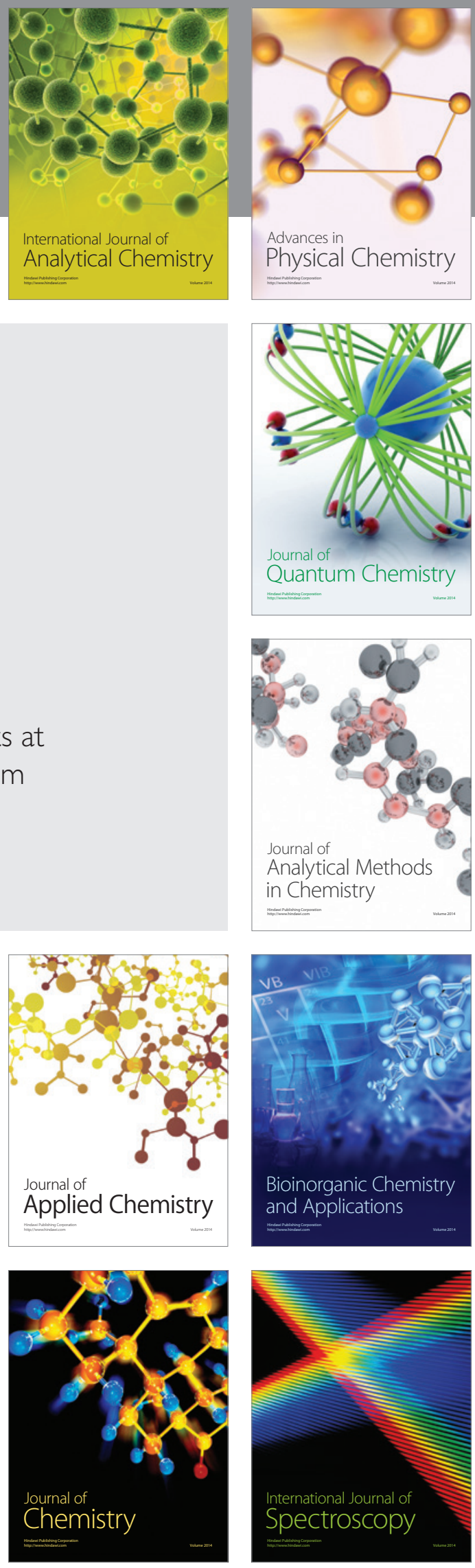